\title{
Tasks of developing the aquatory for testing autonomus ships in inland waterways
}

\author{
Vladimir Karetnikov ${ }^{1}$, Gleb Chistyakov ${ }^{2}$, Evgeniy Ol'khovik ${ }^{1, *}$ \\ ${ }^{1}$ Admiral Makarov State University of Maritime and Inland Shipping, 5/7 Dvinskaya, Saint- \\ Petersburg, 198035, Russia \\ ${ }^{2}$ Volga-Balt State Basin Administration, 15B Vilenskiy, Saint-Petersburg, 191014, Russia
}

\begin{abstract}
For successful implementation of unmanned technologies on water transport, it is proposed to create a specialized test area where autonomus ships and technologies of autonomus navigation could be tested in real conditions. The paper considers the solution of the problem of placement and technical equipment of the test aquatory, provided that risks are minimized, including collision prevention and environmental damage. To select the location of this aquatory, the features of the inland waterways of the European part of the Russian Federation were analyzed and the requirements for this water area were formulated. As a result, two test sites were proposed that allow for all the necessary types of tests of autonomus ships. The paper synthesizes the main parameters, such as the availability of navigation and hydrographic information, electronic cartography, etc. As a result of the study, a site in lake Ladoga was selected. In order to complete the full cycle of necessary measures during the tests and ensure the safety of navigation in a given area, it was decided to design the test aquatory as a set of three maneuvering zones for an unmanned vessel: the safe free maneuvering zone during testing, the turning zone - area of restricted maneuverability on courses and speeds, as well as on the shift of the steering wheel, and the extra safety maneuvering area used to prevent navigation accidents in difficult navigation conditions. The proposed location and concept of the test aquatory fully meet all the requirements for such an innovative infrastructure at the international level.
\end{abstract}

\section{Introduction}

Nowadays, there is an active development of unmanned technology on all modes of transport around the world. Sea and inland water transport is no exception. The International Maritime Organization has proposed a strategic development plan until 2023, which separately addresses the development of autonomus shipping. [1]

For successful implementation of modern unmanned technologies on water transport, it is necessary to create specialized water areas that will allow carrying out full-scale tests of autonomus ships and technologies of non-pilotless navigation, in real conditions, taking into account the influence of various external factors. Temporary requirements [2] for tests

\footnotetext{
* Correspondent author: OlhovikEO@gumrf.ru
} 
of autonomus ships were proposed by the Maritime safety committee in 2019 and are being actively discussed both in the technical part [3] and in the field of maritime law [4].

The location and technical equipment of the test areas should allow carrying out fullscale tests and practical approbations in such a way as not to create a danger to ships located in the immediate vicinity. In addition, a high level of safety of navigation in general should be provided. It should be noted here that the parameters of the water area should allow testing and approbation for the entire range of promising autonomus ships and infrastructure facilities.

Experience shows that the development of unmanned water transport management technologies begins at the national level, and then the best practices are adopted by the international community. Test zones are initially placed in coastal marine areas or on inland waterways of the country.

The purpose of this study is to provide a scientific justification for the parameters for creating test areas for testing autonomus ships on inland waterways using the example of the Russian Federation. The objectives of the work are:

- determination of parameters for the optimal location of the test area;

- determination of parameters and level of technical equipment for ensuring safety of navigation in the aquatory of the test water area;

- $\quad$ analysis of waterways, their condition and congestion;

- determination of parameters and types of ships that sail in the selected area;

- determination of restrictions when testing autonomus ships.

All work was performed by employees of the scientific and educational center "Unmanned technologies in water transport" Admiral Makarov SUMIS (https://gumrf.ru/sveden/struct/centr/nc/btnvt) with the assistance of the Volga-Balt state Basin Administration.

\section{Materials and methods}

The existing experience of Norway [5] and Finland [6] was used when selecting a section of inland waterways for placing a test area for testing autonomus ships.

Norway has the greatest experience in creating water areas for testing autonomus ships, three water areas have been created in its territorial waters (another one is being designed and announced for opening) - figure 1. They are located in fjords, have significant depths, technical equipment meets national requirements, and special infrastructure development is planned.

The test site is located in Finland in the coastal zone on the west coast of the country (figure 2).

The longest side of the test zone in the north is approximately $17.85 \mathrm{~km}$, and the western side is approximately $7.10 \mathrm{~km}$. The area is open water and offers opportunities for testing also in ice conditions in winter. The studied characteristics show that the Finnish water area has the most optimal size, but does not allow testing of river autonomus ships. 


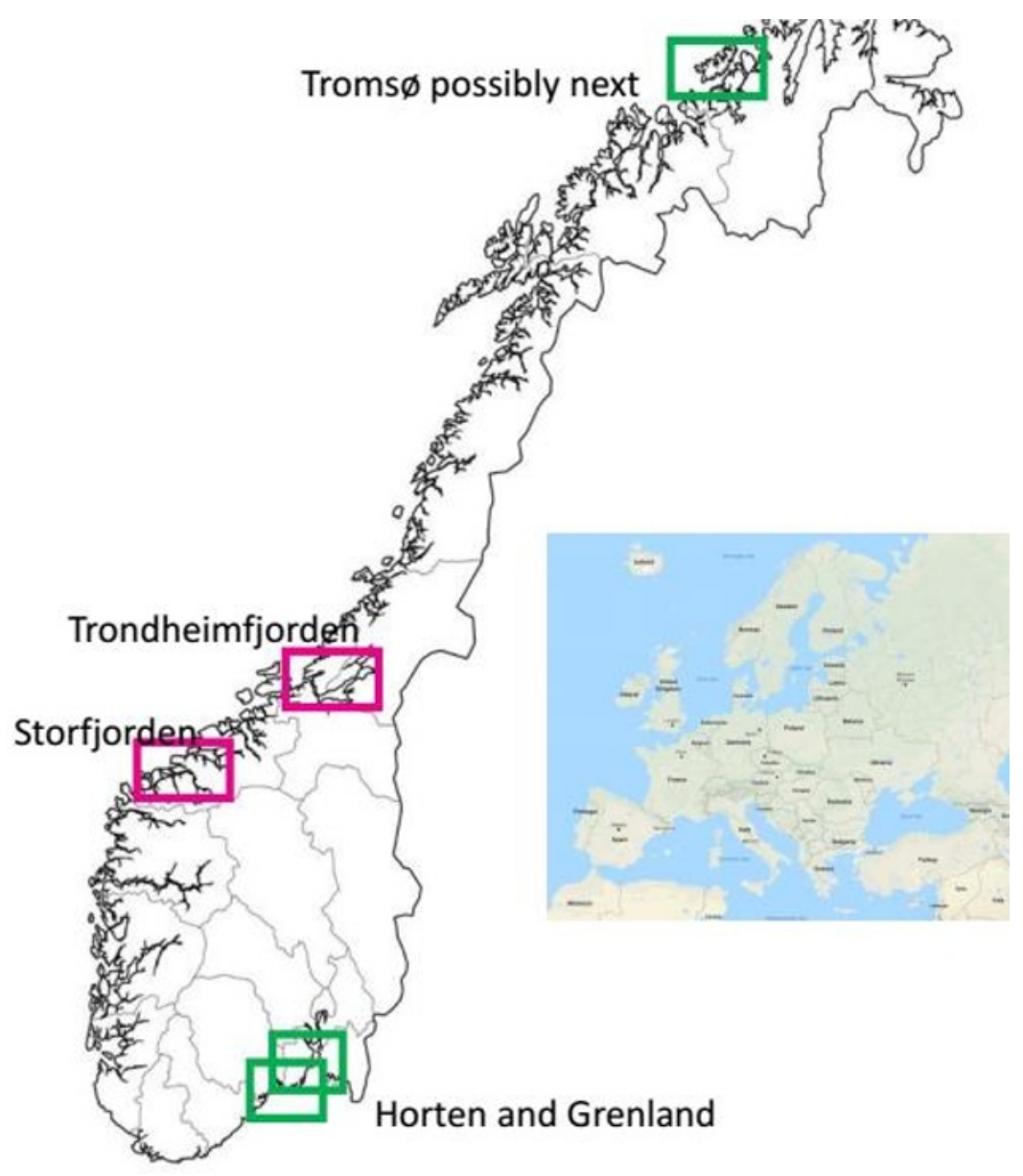

Fig. 1. Location of Norwegian test areas for testing autonomus ships [7]

To justify the characteristics and design of a test water area in the Russian Federation, it is possible to take into account international experience and additionally analyze the following features:

- analysis of the state of inland waterways in the European part of the Russian Federation;

- navigation and hydrographic features that allow testing of autonomus ships of various classes;

- possibilities of technical equipment of the test water area;

- remoteness from the large centers of competence engaged in the development and production of autonomus ships;

- ability to deliver prototypes of autonomus ships of various classes.

All the main estimated parameters form a single methodology, which is graphically presented in figure 3. 


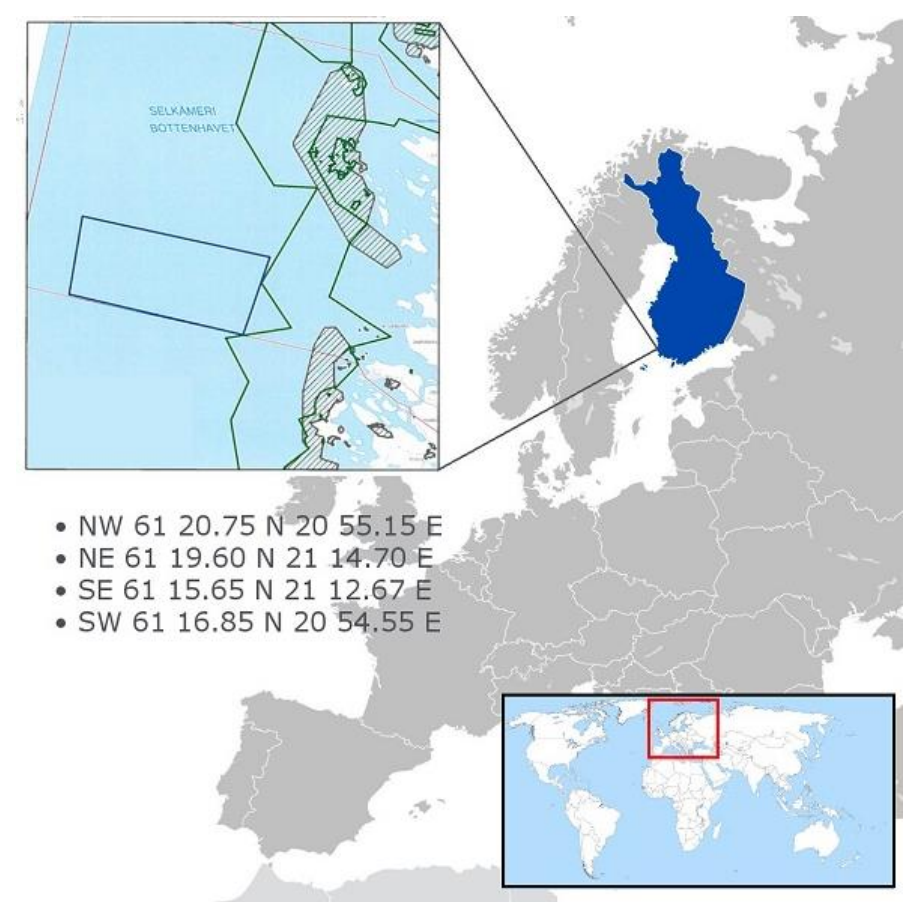

Fig. 2. Location of the water area located in Finland for testing autonomus ships in Botany Bay [8]

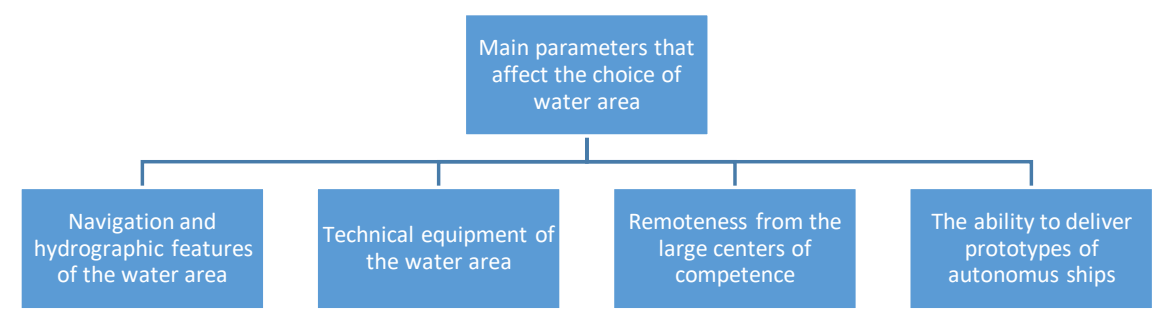

Fig. 3. Synthesis of the main parameters that influence the choice of the test area for testing autonomus ships

In addition, it is proposed to take into account the potential opportunities for implementing autonomus navigation technologies on inland waterways, which are disclosed by us in the works [9.10].

\section{Results}

As a result of the analysis, it was found that the section of waterways included in the area of responsibility of the Volga-Balt State basin administration -Svirskaya Bay of lake Ladoga corresponds most fully to all the criteria in figure 3 .

Since an additional strategic area is testing autonomus ships in ice conditions, it is necessary that the test area allows testing in the presence of ice fields. The selected water area allows testing of this type, ice formation on lake Ladoga occurs in concentric zones from the shore to the center of the lake, the ice reaches its maximum thickness in March. 
Svirskaya Bay is located in the immediate vicinity of the southern route of lake Ladoga, which is the main and busiest route for ship traffic, part of the Volga-Balt waterway.

The analysis of the traffic of ships of various projects that operate on this route both in the forward and reverse direction was carried out. The total number of routs on the southern route of lake Ladoga to Petrokrepost Bay for navigation in 2018 was 1414 routs, and from Petrokrepost Bay to Svirskaya Bay 1341 routs.

On the southern route of lake Ladoga, there is a significant transit of general cargo, fuel oil, metal, timber, malt, construction and non-metallic construction materials.

Thus, the average parameters of the fleet operating in the considered basin were determined. This is necessary to determine the parameters of the water area for autonomus ships tests. It was decided to focus on the "river-sea" class ships with a length of about 140 $\mathrm{m}$. These ships include the "Volga-Don" and "Volga" type ships. The cargo capacity of these ships is about 5000 tons (10 000 tons with a prefix) with open or closed holds. The length of the ships is $140 \mathrm{~m}$, width is $16.5 \mathrm{~m}$, draught is $3.5 \mathrm{~m}$. Main engine power is 2000 $\mathrm{HP}$, empty speed is $21-23 \mathrm{~km} / \mathrm{h}$.

In order to complete the full cycle of necessary measures during the tests and ensure the safety of navigation in the specified area, it was decided to design the test area as a set of 3 maneuvering zones for an autonomus ships (figure 4):

- safe maneuverability area during testing;

- restricted maneuverability area on courses and speeds, as well as on the shift of the steering wheel;

- extra safety area of the manoeuvring to be used to prevent navigation accidents in the difficult conditions of navigation.

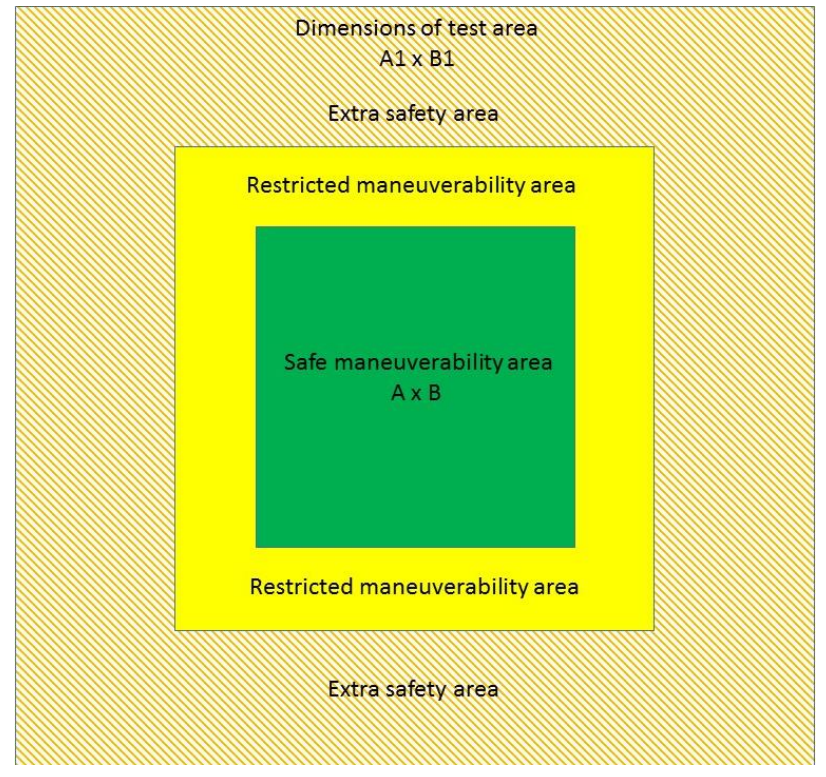

Fig. 4. Dividing the water area for testing autonomus ships into maneuvering zones

The technical equipment of the test area must meet the following requirements:

- availability of control and correction stations of global navigation satellite systems GLONASS / GPS;

- $\quad$ the availability the vehicle navigation equipment;

- availability of a ship traffic management system; 
- $\quad$ availability of a communication system;

- $\quad$ availability of an alarm system;

- availability of a vessel monitoring system;

- $\quad$ availability of coverage of this water area with updated state electronic navigation charts.

The water area under consideration (figure 5) has all the required parameters, and if necessary, allows for fairly rapid retrofitting and modernization.

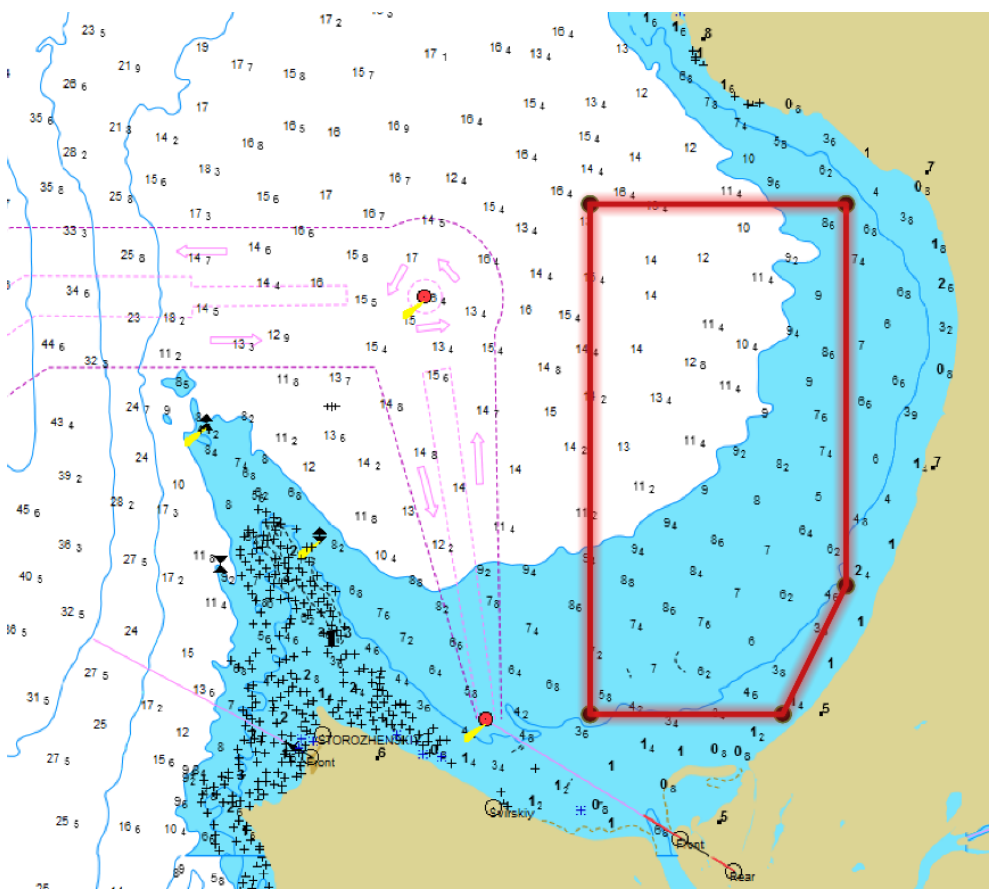

Fig. 5. Fragment of the map of lake Ladoga (Svirskaya Bay) with the design boundaries of the test area for testing autonomus ships

The water area of the Eastern part of lake Ladoga, in the area of Svirskaya Bay, has sufficient guaranteed dimensions, is equipped with beacons with navigation lights, has cellular coverage and updated electronic navigation charts, which allows you to organize a test water area in this aquatory and ensure a sufficient level of safety of navigation during testing and approbation of autonomus and unmanned ships and innovative technological solutions. The technical equipment of the water area under consideration meets all the requirements for it. The size of the designated area is $15 \mathrm{~km} \times 7.5 \mathrm{~km}$, which corresponds to the calculations for the safe free maneuvering zone, the average depth usually exceeds 15 $\mathrm{m}$, the ground is mostly sandy, ice cover is formed in winter, the water area allows testing of all four levels of ship autonomy, according to the IMO classification [1,2].

The location of the water area in lake Ladoga ensures its connection with the Baltic sea via the Neva river and allows it to be used for testing, including autonomus river-sea ships.

\section{Discussion}

It should be noted that in addition to creating full-fledged autonomus cargo ships, the development of robot ships that provide maintenance of waterways, such as hydrographic research, trawling, and location control of navigation equipment, is quite promising. Work 
on the creation of such robot ships is actively underway and they can also be classified as autonomus ships. However, thanks to the introduction of modern technologies, the creation of such robot ships is on the path of miniaturization and most solutions are quite compact samples. It is quite irrational to conduct tests of such equipment samples in the water area of lake Ladoga, so the logical solution is to create an additional test site.

Perhaps a new level of development will be a multi-agent structure [11] to expand the intellectual capabilities of autonomus ships, including remote monitoring [12] and management. In the test area, it will be possible to safely train for automatic mooring [13] and cargo handling, which is also a necessary component when switching to fully automated ships.

To ensure security, new models and risk assessments will be required, which are already being developed [14] and assume partial or complete absence from the human side.

Comparing the technical capabilities of existing test areas - $[5,6]$ and the practice of large-scale demonstrations $[15,16]$ of autonomus marine vehicles, it is necessary to take into account that in order to prevent certain hazards, it makes sense to create several separate water areas within one or adjacent sections of water. Then, an additional factor that indicates the need to create a second site is the absence of a constant current on lake Ladoga. Since the Russian Federation has an extensive network of inland waterways on which autonomus ships will be operated, it is necessary to test them in river conditions.

\section{Conclusions}

Thus, we can conclude that the creation of two test sites (in the water area of the Svirskaya Bay of lake Ladoga and on the river section) as a single testing ground for autonomus ships in the Russian Federation is an important step towards the successful introduction of unmanned transport. The proposed location and concept of the water area meet all the requirements for such infrastructure at the international level.

The authors express their gratitude to the Volga-Balt state basin administration for providing information materials and assistance in conducting this study.

\section{Reference}

1. http://www.imo.org/en/MediaCentre/HotTopics/Pages/Autonomus-shipping.aspx

2. MSC.1/Circ.1604 Interim guidelines for mass trials 14 June 2019

3. K. Kutsuna, H. Ando, T. Nakashima, S. Kuwahara, \& S. Nakamura, Journal of Physics: Conference Series, IOP Publishing, 1357(1), 012013 (2019). doi: 10.1088/1742-6596/1357/1/012013

4. R. Veal, Shipping \& Trade Law, 19(8), 1-5 (2019).

5. World's first test area for autonomus ships opened. Available: https://www.sdir.no/en/news/news-from-the-nma/worlds-first-test-area-for-autonomusships-opened/

6. World Maritime News. First Test Area for Autonomus Ships Opened in Finland (2017). Available: https://worldmaritimenews.com/archives/227275/first-test-area-forautonomus-ships-opened-in-finland/.

7. Jaakonmeri Test Area. Available: https://www.oneseaecosystem.net/test-area/

8. Trondheim autonomus vessels test area. Available: http://navtar.no/

9. V.V. Karetnikov, G.B. Chistyakov, V.A. Bekryashev, Marine radio electronics, 4(70) (2019). 
10. V. Karetnikov, I. Pashchenko and A. Sokolov, Vestnik gosudarstvennogo universiteta morskogo i rechnogo flota imeni admirala S.O. Makarova 3(43), 619-627 (2017). DOI: 10.21821/2309-5180-2017-9-3-619-627

11. Zh. Xiao, Journal of International Maritime Safety, Environmental Affairs, and Shipping 2.2, 43-57 (2019).

12. V. Karetnikov, A. Butsanets, A. Mitrofanova, IOP Conference Series: Earth and Environmental Science, IOP Publishing, 378(1) (2019).

13. A. Butsanets, E. Ol'khovik, 2019 International Multi-Conference on Industrial Engineering and Modern Technologies (FarEastCon). IEEE, (2019).

14. Rødseth, Ørnulf Jan, and Hans-Christoph Burmeister. TransNav, International Journal on Marine Navigation and Safety Od Sea Transportation, 9.3 (2015).

15. Vander Hook, Joshua, et al. "Autonomus swarms of high speed maneuvering surface vessels for the central test evaluation improvement program." Unmanned Systems Technology XXI. Vol. 11021. International Society for Optics and Photonics (2019).

16. Xu, Haitong, Hao Rong, and C. Guedes Soares, Ocean Engineering 194, 106635 (2019). 